\title{
Diagnose and treatment of traumatic pleural-subarachnoid fistula in children: A case report and systematic review
}

\author{
Wei Yang ${ }^{1}$, Ming Ge ${ }^{1^{* *}}$, Chenghao Chen ${ }^{2}$ and Qi Zeng ${ }^{2^{*}+}$
}

\begin{abstract}
Background: Pleural-subarachnoid fistula (PSF) is a rare disease that is difficult to diagnose and treat. Secondary intracranial hypertension and the treatment are seldom mentioned previously among PSF.

Case presentation: A 1-year-old boy diagnosed PSF developed into secondary intracranial hypertension after conservative treatment. He was finally cured by down-step treatment of mannitol, avoiding form ventricleperitoneal shunt. Then, we reviewed the literature of pleural-subarachnoid fistula. Fifty-six cases have been reported so far. Most of the cases (51.8\%) were caused by surgery; only 17.9\% were caused by car accidents. Regarding the treatment, half of the cases cured by surgery and the other by conservative measures. Our case is the first one involving secondary intracranial hypertension and cured by down-step treatment of mannitol.

Conclusions: A comprehensive examination should be performed before the treatment to avoid any inappropriate medical strategies. Secondary acute intracranial hypertension may be cured by down step treatment of mannitol, evading from the long-term ventriculoperitoneal shunt.
\end{abstract}

Keywords: Pleural-subarachnoid fistula, Intracranial hypertension, Treatment, Complications

\section{Background}

Pleural-subarachnoid fistula is a rare and complicated disease, which can be iatrogenic, traumatic, and spontaneous. The symptoms and signs could be a postural headache, mental changes, and dyspnea. The imaging examinations also present variously. Not all imaging examinations of pleural-subarachnoid fistula (PSF) showed pleural effusion; some only showed no significant changes in the pleural cavity or dilatation of the upper mediastinum [1, 2]. A small number of patients had mental changes. The imaging examination will show the pneumocranium on the CT scan and the pneumothorax

\footnotetext{
*Correspondence: Ming_Ge@126.com; zengqi-1@163.com

${ }^{+}$Ming Ge and Qi Zeng contributed equally to this work.

'Department of Neurosurgery, Beijing Children's Hospital, Capital Medical

University, National Center for Children's Health, Beijing 100045, China

${ }^{2}$ Department of Thoracic, Beijing Children's Hospital, Capital Medical

University, 56 South Lishi Road, Xicheng District, Beijing 100045, China
}

on the chest X-ray [3-10]. Myelography, CT myelography, spinal MR, $\beta-2$ transferrin, and biochemical analysis of pleural effusion can be used to assist the diagnosis of PSF. As for treatment, surgery and non-surgery treatment both have been reported as an available measurement. In this article, we described a 1-year-old boy with persistent pleural effusion caused by a car accident who was confirmed to be PSF by myelography. PSF was cured by the lumbar cistern and thoracic drainage for about 2 months. After that, he experienced secondary acute intracranial hypertension. A down step of mannitol was used, and the intracranial hypertension was under control finally. After a 1-year follow-up, there are no any recurrent of PSF and intracranial hypertension signs.

C C The Author(s). 2020 Open Access This article is licensed under a Creative Commons Attribution 4.0 International License, which permits use, sharing, adaptation, distribution and reproduction in any medium or format, as long as you give appropriate credit to the original author(s) and the source, provide a link to the Creative Commons licence, and indicate if changes were made. The images or other third party material in this article are included in the article's Creative Commons licence, unless indicated otherwise in a credit line to the material. If material is not included in the article's Creative Commons licence and your intended use is not permitted by statutory regulation or exceeds the permitted use, you will need to obtain permission directly from the copyright holder. To view a copy of this licence, visit http://creativecommons.org/licenses/by/4.0/ The Creative Commons Public Domain Dedication waiver (http://creativecommons.org/publicdomain/zero/1.0/) applies to the data made available in this article, unless otherwise stated in a credit line to the data. 


\section{Case presentation}

\section{Medical history}

A 21-month-old boy with thorax drainage was admitted to our medical center for massive pleural effusion lasting for 1 month approximately for an unknown reason. One month ago, the boy experienced a car accident, and his chest hit against the airbag. Then, he was sent to the local emergent rescue. An instant CT scan showed a hydrops area in the abdominal and chest. Then, an exploratory laparotomy was performed, and spleen rupture and retroperitoneal hematoma were found during the surgery. The boy experienced a splenectomy, and drainage was placed for pleural in the thorax. Subsequently, he experienced persistent pleural effusion. The chest tube drained 400-600 ml every day, and the fluid was clear. The child kept a good mental state and did not complain about anything. He had been fasting for a few days in the previous hospital for the consideration of chylothorax diagnosis, but the pleural effusion did not reduce obviously. In our medical center, chylothorax, pleural-subarachnoid fistula, and urine leakage were taken into differential diagnoses according to the history of trauma and surgery.

The biochemical analyses of the thorax fluid are as follows: Rivalta test (-); WBC, $64 \times 10^{6} / \mathrm{L}$; mononuclear cells counts, 14; multinucleated cell counts, 50; total protein, $1.5 \mathrm{~g} / \mathrm{L}$; lactic dehydrogenase, $61 \mathrm{U} / \mathrm{L}$; adenosine deaminase, $0.1 \mathrm{U} / \mathrm{L}$; glucose, $4.64 \mathrm{mmol} / \mathrm{L}$; and creatinine, $33.3 \mathrm{umol} / \mathrm{L}$.

The chest radiography showed massive pleural effusion in the right thorax. B ultrasound of the urinary system did not show any abnormity. The heavily T2 MR of the spine suspected a fistula at the T11 level. Brain CT did not present any positive findings (Fig. 1).

\section{Treatment and follow-up result}

To distinguish it from chylothorax, the child was allowed to eat some food. However, we did not see any changes to the drainage. Combined with the negative Rivalta test and clear color of drainage, the chylothorax was excluded. Furthermore, the creatinine was not at a similarly high level as the urine. Due to a positive finding from heavily $\mathrm{T} 2$ spine $\mathrm{MR}$, the most likely diagnosis would be PSF. A thorax endoscopy exploratory surgery was performed to demonstrate the diagnosis and expecting to find the fistula and repair it. However, we failed to repair the fistula due to the desperate difficulty to find the lesion. To further confirm the diagnosis of PSF, myelography was performed and reassured the pleuralsubarachnoid fistula at T11 level (Fig. 2). Meanwhile, we performed lumbar cisternal drainage to relieve the pressure of the cerebrospinal fluid (CSF), which could benefit the natural repairment of PSF theoretically. The drainage of the thorax and lumbar cisternal were about $200 \mathrm{ml}$ and 460 every day. The total volume always went around 400-600 $\mathrm{ml}$. Three weeks later, the drainage of the thorax decreased to nearly zero suddenly, but the drainage of the lumbar cisternal was around 400-600 ml. Two more weeks later, we removed the chest tube and elevated the level of the lumbar cisternal drainage gradually, and there was no pleural effusion ever (Fig. 3). The drainage volume decreased as the height elevated. We removed the lumbar cisternal drainage 5 days later. During this period, the antibiotic was used to prevent infection, so the child did not catch any infection.

One day after the removal of the lumbar cisternal drainage, the boy became agitated and fell into lethargy. Acute intracranial hypertension was considered due to the lumbar puncture showing more than $300 \mathrm{~mm} \mathrm{H}_{2} \mathrm{O}$ of pressure, and the test of CFS did not show the

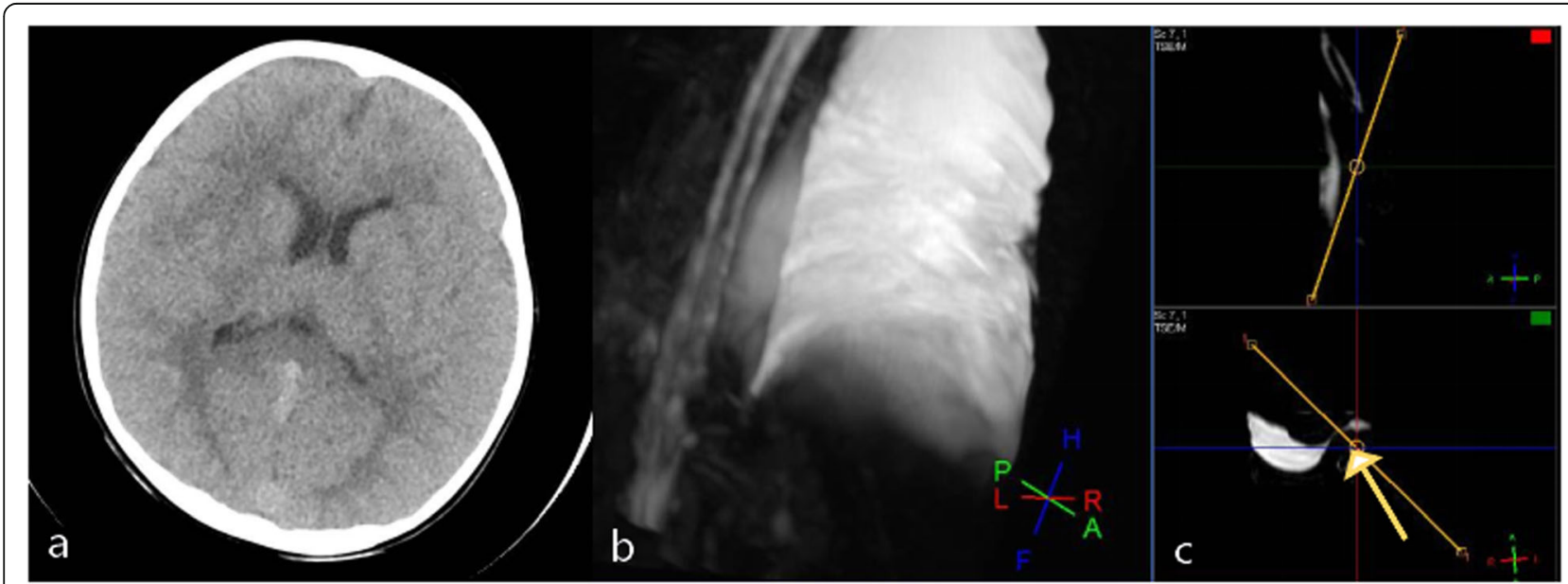

Fig. 1 a-c Brain $C T$ and heavily $T 2$ spine MR. a No abnormal signs on brain CT. b, c The arrow in heavily spine MR shows the suspected fistula signal between at T11 level 


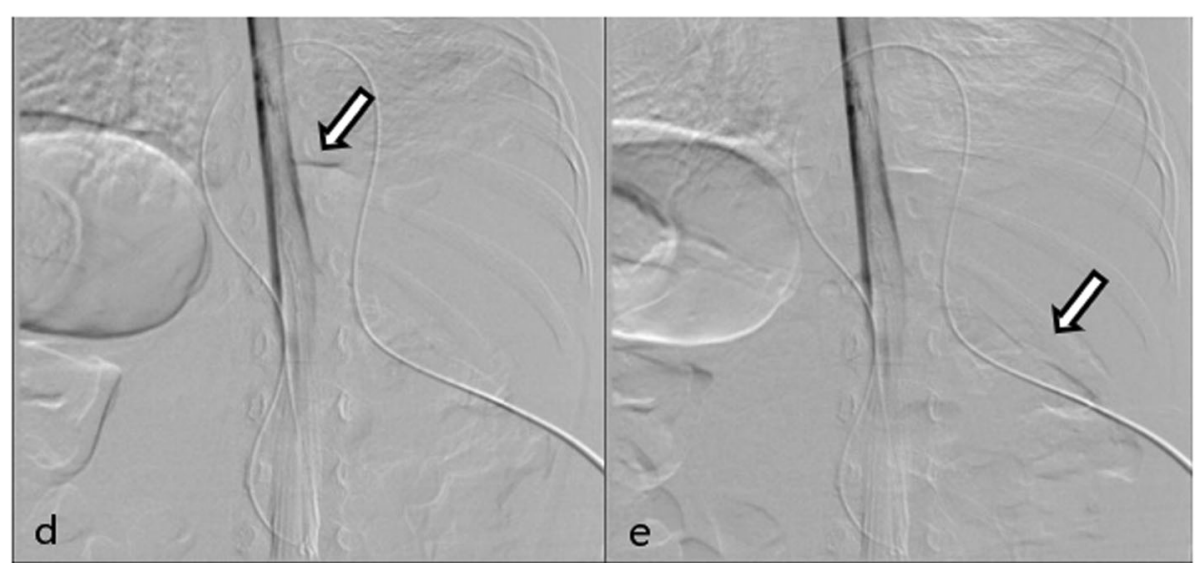

Fig. $2 \mathbf{d}$-e Myelography. $\mathbf{d}$-e The arrows show the contrast agents leaking from the subarachnoid space to the thorax

features of infection. So mannitol was given $10 \mathrm{ml} / \mathrm{kg}$ Q8h. An MR scan of the head did not show dilation of the ventricle and paraventricular edema (Fig. 3). The boy got back to normal state quickly, and his mental status got worse when we stopped the mannitol treatment at the early stage. This meant that he was involved in stubborn intracranial hypertension and mannitol had become a necessity for him. A ventriculoperitoneal shunt once was considered as a treatment to the secondary acute intracranial hypertension. However, his parents refused to carry the movement. Then, we tried the down step of mannitol treatment, and we stopped the mannitol 2 weeks later. The boy did not complain about any headache. And the re-chest X-ray was normal. After 1 year following, he has not shown pleural effusion again and intracranial hypertension.

A total of 56 cases were initially retrieved through the database search. All the papers were fully read, and we collected and summarized all the etiology,
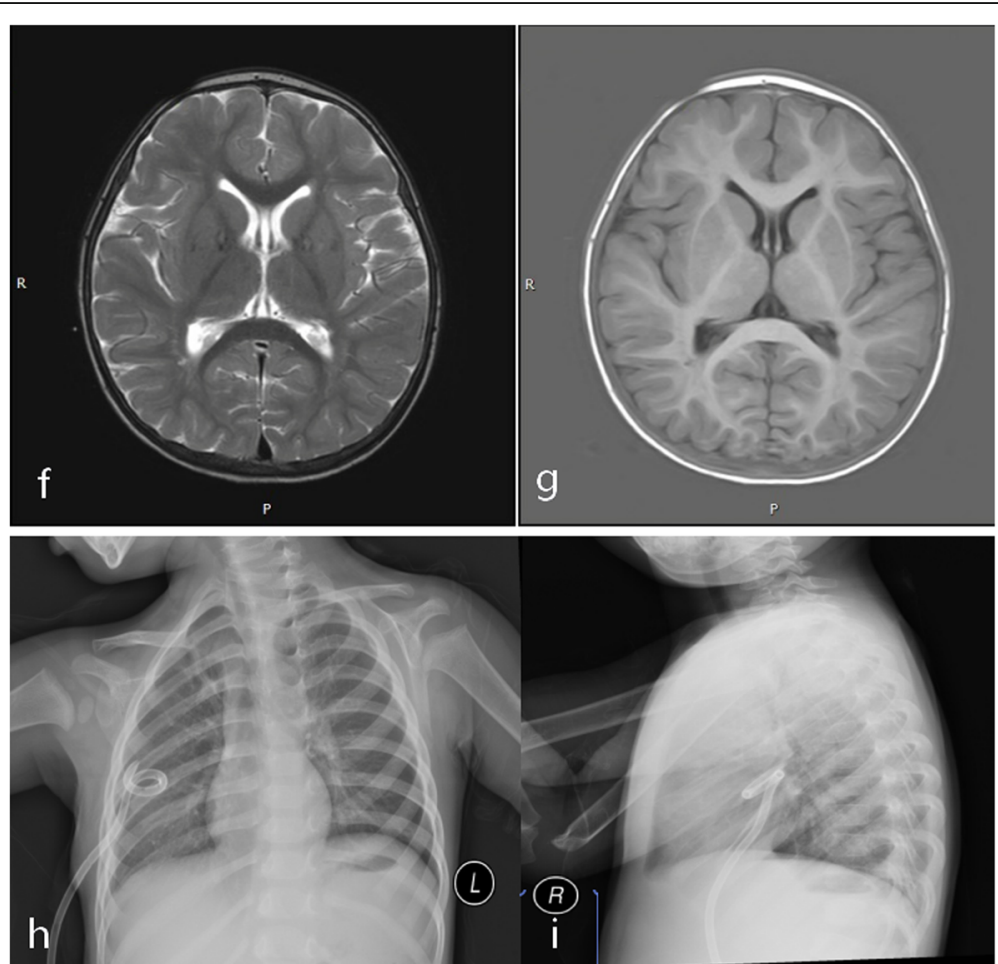

Fig. $3 \mathbf{f}-\mathbf{i}$ Chest $X$-ray and brain MRI. $\mathbf{f}, \mathbf{g}$ The MRIs show no ventriculomegaly or paraventricular edema after removal of cisternal drainage. $\mathbf{h}$, $\mathrm{i}$ The chest $X$-ray show the no effusion in the thorax 
manifestations, detection measures, and treatment methods. The most common cause of PSF (Table 1) was medical operation (51.8\%), especially in spinal operation. The following causes were injury (26.8, especially refer gunshot), car accident (17.9\%), and other rare events (3.6\%, such as massage, tumor infiltration). As for clinical manifestation (Table 2), continuous or massive pleural effusion was the most common one (74.1\%). About $10.3 \%$ of patients show pneumocephalus, and $8.6 \%$ of patients present with hemopneumothorax. Only a few patients featured by posture headache or upper mediastinum. There were some techniques (Table 3) used by doctors to make a diagnosis of PSF. Radioisotope myelography is the most effective means. Heavy T2-weighted myelography $\mathrm{MR}$ is a new non-invasive method to detect the fistula with a positive rate at $88.9 \%$. The other techniques are $\beta 2$ transferrin $(85.7 \%)$, CT myelography (83.3\%), and myelography (66.7\%). For all the 56 patients, $57.1 \%$ of the patients received surgical treatment (Table 4), including through the thorax route $(40.8 \%)$ and through the laminar route (14.3\%). The other patients were cured by different kinds of conservative treatments, and the most popular one was drainage.

\section{Discussion}

The pleural-subarachnoid fistula was first reported by Milloy et al. [11] in 1959. The clinical manifestations of PSF can be very diverse. Continuous pleural effusion (74.1\% of the cases) is the most common manifestations of PSF. Pneumocephalus and pneumothorax without pleural effusion consist of $10.3 \%$ of the cases [8]. They remain present with hemopneumothorax postured headache [12], or just a dilation of the upper mediastinum [2]. The cerebrospinal fluid is sucked into the thorax due to the lower pressure in the thorax cavity. Besides, pleural effusion may come from the thoracic lymphatic system, urine from the injured urinary system, transudate from the vascular system, infectious exudate. PSF, urine, and chylothorax are always characterized by continuous liquid or massive volume. The difference is the color of the liquid. PSF is generally clear, and urine can be clear or urine color, and chylothorax is always milky and will change with food intake. Apart from the color, a negative Rivalta test could be used to distinguish transudate and exudate. PSF thus should be taken into consideration in continuous pleural effusion circumstance,

Table 1 Etiology of PSF

\begin{tabular}{ll}
\hline Etiology & Percentage (number) \\
\hline latrogenic & $51.8 \%(29)$ \\
Injury & $26.8 \%(15)$ \\
Car accident & $17.8 \%(10)$ \\
others & $3.6 \%(2)$ \\
\hline
\end{tabular}

Table 2 Manifestation of PSF

\begin{tabular}{ll}
\hline Manifestation & Percentage (\%) \\
\hline Pleural effusion & 74.1 \\
Pneumocephalus & 10.3 \\
Hemopneumothorax & 8.6 \\
Postured headache & 5.3 \\
Upper mediastinum dilation & 1.7 \\
\hline
\end{tabular}

especially when the Rivalta test is negative. However, to confirm the diagnosis, further examinations should be taken.

Several techniques have been developed to assist the diagnosis of PSF, which include $\beta 2$ transferrin, special MR of the spin, myelography, CT myelography, and radioisotope myelography. In this review, we made a summary of the sensitivity of all the techniques and found that they should be performed in an appropriate sequence. In terms of positive rate, radioisotope myelography $(100 \%)$ is the most effective method. In this review, all the patients who did this examination showed positive results. However, this kind of an examination has more radiation damage to the human body, compared with other measures. There is a special sequence of MR which has been applied to discover the PSF, with a positive rate at $88.9 \%$, higher than CT myelography and myelography, which are at $83.3 \%$ and $66.7 \%$, respectively. Nearly every technique has a potential negative rate, so they should be used with a comprehensive sequence during the diagnose procedure according to sensitivity and harmfulness. $\beta 2$ transferrin should be taken into consideration firstly as a non-invasive and handy test. If these examinations fail, and a PSF is strongly suspected, the probe surgery can be performed for diagnosis and treatment. However, fistulas were not visible during surgery $[3,13]$ sometimes.

Treatments for PSF include surgery and non-surgery. Although surgical treatment is a little more common than non-surgery strategy, there are more kinds of conservative measurements including thorax drainage, lumbar cisterna drainage, keeping supine position [10], epidural blood patch $[12,14]$, positive pressure ventilation [15-18], biological glue injection percutaneously $[19,20]$, and so on. Percutaneous injection of biological glue was newly reported treatment. As a minimally

Table 3 Examination technique for diagnosis

\begin{tabular}{ll}
\hline Examination technique & Positive rate (\%) \\
\hline Radioisotope myelography & 100 \\
Heavy T2-weighted myelography MR & 88.9 \\
$\beta 2$ transferrin & 85.7 \\
CT myelography & 83.3 \\
Myelography & 66.7 \\
\hline
\end{tabular}


Table 4 Treatment of PSF

\begin{tabular}{ll}
\hline Treatment & Percentage (\%) \\
\hline Surgery & 57.1 \\
Through thorax & 40.8 \\
Through laminar & 14.3 \\
Thorax-peritoneal shunt & 2.0 \\
Non-surgery & 42.9 \\
Drainage & 24.5 \\
NPPV & 10.2 \\
Injection of the biological glue & 4.1 \\
Epidural blood patch & 4.1 \\
\hline
\end{tabular}

invasive treatment, it will be a promising strategy. In a word, doctors are attempting to find more and more conservative methods to treat the PSF due to the difficulty to find the lesion during operation, especially for traumatic PSF. Of course, open surgery is suitable for large fistula, which is difficult to be cured by nonsurgical measures [21]. Each method has its pros and cons. Doctors should choose a suitable method according to medical history and the type of fistula. Of course, Conservative strategies may spend more hospital days and have a risk of infection.

Complications related to the treating measure were seldom reported before. Knafo et al. [20] reported the thorax pain after injection of onyx. Infection [22] and neurological defects [4] were reported separately by Wilson and Jumer and Brown and Symbas. Milloy et al. [11] reported a 19-year-old man complaining headache after repairing the pleural-subarachnoid fistula. The reason may be that this patient experienced pleural effusion for about 8 months. The balance of cerebral-spinal fluid (CSF) circulation had changed before surgery, so the closure of the fistula might result in intracranial hypertension. In our case, the patient progressed headache and coma after the removal of the lumbar cisternal drainage. A lumbar puncture was carried, and it demonstrates the patient was in hyper intracranial tension state. This may be because long-term of cisternal drainage has created a new balance of CSF. After removing the cisternal tube, CSF could not outflow from the lumbar cisternal tube, so CSF pressure increased sharply. And this caused a headache and coma state. Generally, doctors would perform V-P shunt as a solution to this situation. We once managed to do so. But the patient's parents refuse to do so. So we tried the down step of mannitol treatment; the boy was cured finally. In fact, among the published article, researchers always perform the V-P shunt in the similar situations. A down step of mannitol treatment is seldom described to treat such serious secondary acute intracranial hypertension. This indicates that children have a more powerful ability to build a new balance of CSF. And in the face of secondary intracranial hypertension, we should choose V-P shunt more carefully.

\section{Conclusion}

The PSF is a very rare situation that can be difficult to diagnose and treat. PSF should be taken into consideration in a continuous pleural effusion situation. A fullscale and sequenced examination should be performed to assist the diagnosis of PSF. The treatment strategy should be based on clinical features. Intracranial hypertension after the closure of the fistula should be treated seriously. The down-step of mannitol should be tried first before the V-P shunt.

\section{Abbreviations \\ PSF: Pleural subarachnoid fistula; NPPV: Noninvasive positive pressure ventilation; CSF: Cerebrospinal fluid; CT: Computer tomography; \\ MR: Magnetic resonance}

\section{Acknowledgements}

We thank the staff of the Thoracic Department for their efforts in the treatment of this patient.

\section{Authors' contributions}

WY and CHC collected the data online and wrote the article. MG and QZ conceived and instructed throughout the process and participated in the revision of the article. All authors read and approved the final manuscript. MG and QZ share the same contribution to this study, so they should share being the corresponding authors.

\section{Funding}

No

Availability of data and materials

Please contact the author for data request.

Ethics approval and consent to participate

Not applicable.

\section{Consent for publication}

The work was done with the informed consent of the patient's parents.

\section{Competing interests}

The authors declare that they have no competing interests.

Received: 16 September 2019 Accepted: 24 June 2020

Published online: 06 August 2020

\section{References}

1. Heller JG, Kim HS, Carlson GW. Subarachnoid--pleural fistulae--management with a transdiaphragmatic pedicled greater omental flap: report of two cases. Spine. 2001;26:1809-13.

2. Moss MS, Wingate JP. Case of the month: that's torn it! Br J Radiol. 1996;69: 479-80, https://doi.org/10.1259/0007-1285-69-821-479.

3. Asner S, Chapuis-Taillard C, Ris HB, et al. Pneumocephalus and pneumococcal meningitis after thoracic surgery. Asian Cardiovasc Thoracic Ann. 2011;19:346-8. https://doi.org/10.1177/0218492311407796.

4. Brown WM 3rd, Symbas PN. Pneumocephalus complicating routine thoracotomy: symptoms, diagnosis and management. Ann Thorac Surg. 1995;59:234-6.

5. de Olaiz NB, Leon Atance P, Alix TA. Pneumocephalus and cerebrospinal fluid fistula following removal of a superior sulcus tumor (pancoast tumor). Arch Bronconeumol. 2004:40:422-5.

6. Kairinos N, Nicol A, Navsaria P. Pneumocephalus following gunshot injury to the thoracic vertebral column: a case report. Ulus Travma Acil Cerrahi Derg. 2009;15:614-6. 
7. Ladehoff M, Zachow D, Koch C, et al. Cerebellar haemorrhage and tension pneumocephalus after resection of a Pancoast tumour. Acta Neurochir. 2005;147:561-4;discussion 564. https://doi.org/10.1007/s00701-004-0402-5.

8. Leone MA, Stecco A, Tesser F, et al. Pneumocephalus from bronchopleuralsubarachnoid fistula. Eur Neurol. 2004;52:253-4. https://doi.org/10.1159/ 000082372.

9. Liang MK, Moore EE, Williams AM, et al. Traumatic subarachnoid pleural fistula. J Trauma. 2008;65:1155-61. https://doi.org/10.1097/01.ta.0000209408. 26575.7a.

10. Bilsky MH, Downey RJ, Kaplitt MG, et al. Tension pneumocephalus resulting from iatrogenic subarachnoid-pleural fistulae: report of three cases. Ann Thorac Surg. 2001;71:455-7.

11. Milloy FJ, Correll NO, Langston HT. Persistent subarachnoid-pleural space fistula; report of a case. J Am Med Assoc. 1959;169:1467.

12. Lin SF, Weng HY. Postural headaches due to cerebrospinal fluid leakage through subarachnoid-pleural fistula: a case report. Headache. 2017;57:46771. https://doi.org/10.1111/head.12974.

13. Bramwit DN, Schmelka DD. Traumatic subarachnoid-pleural fistula. Radiology. 1967;89:737-8. https://doi.org/10.1148/89.4.737.

14. Wu HY, Hseu SS, Chen SP, et al. Spontaneous intracranial hypotension complicated by malignancyinduced disseminated intravascular coagulation: a case report. Acta Neurol Taiwanica. 2016;25:95-8.

15. Kurata Y, Yoshimoto M, Takebayashi T, et al. Subarachnoid-pleural fistula treated with noninvasive positive pressure ventilation: a two-case report and literature review. Spine. 2010;35:E908-11.

16. Schlag HR, Muquit S, Hristov TB, et al. Subarachnoidal pleural fistula after resection of intradural thoracic disc herniation and multimodal treatment with noninvasive positive pressure ventilation (NPPV). Eur Spine J. 2016;25: 155-9. https://doi.org/10.1007/s00586-015-4137-1.

17. Valla FV. Subarachnoid-pleural fistula in an infant treated with mechanical positive-pressure ventilation. Pediatr Crit Care Med. 2007;8:386-8. https://doi org/10.1097/01.PCC.0000262800.57589.40.

18. Yoshor D, Gentry JB, LeMaire SA, et al. Subarachnoid-pleural fistula treated with noninvasive positive-pressure ventilation, Case Report. J Neurosurg. 2001:94:319-22

19. Chu JK, Miller BA, Bazylewicz MP, et al. Repair of a traumatic subarachnoidpleural fistula with the percutaneous injection of fibrin glue in a 2-year-old. J Neurosurg Pediatr. 2016;17:13-8. https://doi.org/10.3171/2015.5. PEDS15194.

20. Knafo $S$, Parker $F$, Herbrecht $A$, et al. Percutaneous treatment of subarachnoid-pleural fistula with Onyx. J Neurosurg Spine. 2013;18:378-81. https://doi.org/10.3171/2013.1.SPINE12628.

21. Karabayir N, Demirkol D, Al IO, et al. Subarachnoid-pleural fistula in a child: the cause and treatment. Pediatr Int. 2012;54:929-31. https://doi.org/10. 1111/j.1442-200X.2012.03600.x.

22. Wilson C, Jumer M. Traumatic spinal-pleural fistula. Jama. 1962;179:812-3.

Ready to submit your research? Choose BMC and benefit from:

- fast, convenient online submission

- thorough peer review by experienced researchers in your field

- rapid publication on acceptance

- support for research data, including large and complex data types

- gold Open Access which fosters wider collaboration and increased citations

- maximum visibility for your research: over $100 \mathrm{M}$ website views per year

At $\mathrm{BMC}$, research is always in progress.

Learn more biomedcentral.com/submissions 